\title{
DUAS VANGUARDAS NA PERIFERIA DO CAPITALISMO
}

Vanguardas em retrocesso. (2012). Sérgio Miceli. São Paulo:

Companhia das Letras, 240 p.

É particular o lugar que Vanguardas em retrocesso: ensaios de história social e intelectual do modernismo latino-americano (2012) ocupa na importante trajetória intelectual de Sérgio Miceli. Se, por um lado, o livro revisita temas centrais de suas obras anteriores, como o modernismo literário e pictórico brasileiro (Intelectuais e classes dirigentes no Brasil e Nacional estrangeiro, por exemplo) e a institucionalização das ciências sociais no país (História das ciências sociais no Brasil), por outro aponta para um relativamente novo e desafiador horizonte de pesquisas, relacionado à sempre delicada comparação entre contextos nacionais distintos, no caso, Brasil e Argentina. A novidade é relativa porque o interesse de Miceli nessa abordagem comparada já existe há mais de dez anos, como explica o próprio autor no interessante "Prólogo" que abre o livro. Se é verdade que Vanguardas é composto de artigos já apresentados ou publicados anteriormente, ainda que com modificações, a bem-vinda edição em livro - com o caderno de imagens já tradicional às obras de $\mathrm{Mi}$ celi - tem não apenas o mérito de tornar os textos acessíveis aos leitores brasileiros (alguns dos artigos haviam sido publicados apenas em espanhol ou francês). É, principalmente, útil aos pesquisadores da sociologia dos intelectuais, do pensamento social e demais áreas interessadas por articular um substantivo programa de investigações, com questões muito claras e que são perseguidas capítulo após capítulo, a uma esclarecedora apresentação dos "bastidores do tra- 
balho" (Miceli, 2012: Io), uma espécie de "passo a passo" da constituição de uma pesquisa, sobretudo em seus termos metodológicos.

A condição periférica de Brasil e Argentina atua como o ponto de partida mais geral que, em grande medida, organiza o argumento que dá título ao livro. A falta de autonomia na constituição do incipiente campo intelectual dos países latino-americanos exigiu arranjos necessariamente distintos dos casos clássicos europeus, o que trouxe consequências sérias para o imaginário criativo das vanguardas locais. A característica da "gênese do nacionalismo literário" dos dois países analisados reside no fato de que "a atividade literária só pôde germinar ao abrigo das benesses e proteções concedidas pelos grupos detentores do poder econômico e político, acoplada à prestação de serviços burocráticos e simbólicos" (Miceli, 2012: 22). A lógica vale para as vanguardas do início do século passado, incapazes de se desvincular dos acordos políticos, da sombra das oligarquias e das sinecuras oferecidas. Daí Miceli ressaltar a centralidade do estudo do mecenato, da morfologia social dos artífices dos movimentos culturais e das ligações dos escritores e artistas com a ambiência europeia que lhes era contemporânea, de modo a dar conta dos fatores condicionantes das vanguardas latino-americanas. Uma vez reconhecida a particularidade periférica comum e a dinâmica produzida por essa posição, o autor faz notar que as diferenças entre os dois contextos específicos reside muito mais em quem são os mediadores político-econômicos interessados ou capazes de fornecer as condições necessárias para que vicejem os projetos culturais: no Brasil, os líderes dos partidos políticos e chefes burocráticos e oligárquicos, ou seja, o Estado como agente privilegiado; na Argentina, o mecenato particular, sobretudo vinculado aos grandes jornais, também eles amplamente ligados ao jogo partidário.

O que caracteriza, portanto, as vanguardas brasileiras e argentinas, segundo Miceli, seria esse enredamento inevitável com os grandes grupos dos poderosos, dos quais os artistas, por mais desprendidos que aparentassem ser, jamais conseguiram se desvincular totalmente. Neste raciocínio, as vanguardas não passariam de "fachada", espécie de subterfúgio esteticamente inovador de oligarquias que anteviam sua decadência. Para arredondarmos numa fórmula que o próprio autor considera "algo brutal", "poder-se-ia dizer que os vanguardistas brasileiros e argentinos eram caudatários, ainda que disso não tivessem plena ciência, de um movimento pujante de reação oligárquica que lhes permitiu empalmar, em sintonia com os móveis de luta cultural desses grupos ameaçados, uma postura estética renovadora como fachada produtiva de uma prática política regressiva" (Miceli, 2012: 37). A virulência com que surgem os novos padrões poéticos e pictóricos dos anos I920 faria, assim, coro a uma espécie de apologética de um mundo social que entrava em declínio. Vanguardas na retaguarda. 
O desenvolvimento peculiar da vida cultural em que nascem as vanguardas latino-americanas implica, portanto, um imbricado jogo de contraprestações, em um cipoal de favores e dívidas cujo rebote na produção artística e no grau de autonomia intelectual torna-se inevitável. Se este é o quadro mais geral, é apenas no estudo dos casos particulares, no entanto, que se consegue perceber os meandros desses mecanismos operando empiricamente; afinal, para usarmos um termo bastante caro ao autor, toda esta dinâmica complexa é "negociada", a atualização prática de um arranjo específico dentre as várias possibilidades oferecidas. Neste sentido, a escolha dos escritores, pintores ou sociólogos estudados está longe de ser aleatória. Pelo contrário, todos eles têm em comum o fato de ocuparem "posições em falso" no espaço social, o que os leva a estarem sempre mais atentos aos automatismos e recorrerem constantemente a estratégias, em alguns casos mais e em outros menos conscientes, na tentativa de alterarem ou estabilizarem suas posições e expectativas.

O livro é organizado a partir da comparação de pares de artistas e intelectuais em posições homólogas no Brasil e na Argentina. Os dois primeiros capítulos, "Jorge Luis Borges - História social de um escritor nato" e "O nacionalismo cultural do jovem Borges", tratam exclusivamente do escritor argentino, claramente o autor a quem Miceli mais se esmerou em suas pesquisas (os dois capítulos ocupam mais de um terço da publicação). Em seguida, Mario de Andrade é analisado, em "Mário de Andrade - A invenção do moderno intelectual brasileiro", ao que se segue um pequeno "Pós-escrito" em que os dois "guias esclarecidos" (Miceli, 20I2: II7) das vanguardas estudadas são colocados lado a lado, em suas condições de "primos pobres" (Miceli, 20I2: I 20) capazes de converter situações aparentemente desfavoráveis (famílias decadentes, autodidatismo, traumas de infância, solteirice etc.) em um prestígio intelectual sui generis.

Não é à toa que sejam estes os autores que abrem o livro. O esforço dos dois escritores em revestir suas figuras públicas com certa aura inefável, como se fossem intelectuais "puros", distantes dos jogos e condicionantes de seu tempo (versão que teria sido comprada por ampla parcela da crítica literária, segundo Miceli), faz deles alvos preferenciais do escrutínio altamente "antiessencialista" do sociólogo, que a todo tempo reivindica a precedência do social sobre a criação artística. Ao contrário da visão imaculada, o quadro que temos após as minuciosas reconstituições dos trunfos e limites familiares de cada autor, das particularidades de suas formações culturais, das oportunidades aproveitadas, das articulações políticas habilmente costuradas, aponta justamente para o caráter eminentemente construído e até planejado (ainda que nunca de maneira teleológica) de suas posições nos campos culturais respectivos. Os variados registros em que atuaram $\mathrm{Ma}$ rio e Borges podem ser lidos, nesta 
chave, menos como uma propensão genial, e, sim, enquanto estratégia bem-sucedida de contornar suas "posições em falso" através do máximo aproveitamento de todos os flancos que se abrissem à sua frente.

O que torna a análise ainda mais interessante é a incursão de Miceli na produção textual dos autores. Ainda que com alcances muito desiguais, dada a maior atenção concedida à obra de Borges, é justamente a partir do corpo a corpo com os textos, sobretudo com as poesias, que o estudo das trajetórias alcança maior força, pois descortina-se de que maneira os enredamentos e as tomadas de posição daqueles escritores repercutiram na suas produções artísticas, contribuindo, assim, para conspurcar as autoimagens universalizantes. Lendo, por exemplo, Fervor em Buenos Aires, livro de estreia de Borges, Miceli identifica uma série de topoi conservadores e críticas sutis à modernização argentina, que ameaçava a posição de classe do autor, como a valorização dos bairros mais afastados ou a simpatia pelos criollos em detrimento dos imigrantes. Mario, por sua vez, tomando igualmente a cidade enquanto lócus privilegiado para entender as mudanças em curso, encheria Paulicéia desuairada de referências às novas forças urbanas que emergiam - imigrantes, empresários, operários -, ainda que sua mirada fosse mais ambígua, em parte devido à sua formação e inserção mais complexa no universo de valores local. Em poucas palavras, as figuras de Mario e Borges representariam, na leitura de Miceli, “os heróis lendários da crise do poder oligárquico, os derradeiros porta-vozes de um mundo em desmonte, nutridos por um estilo de vida e de pensamento golpeado de morte" (Miceli, 2012: I22).

No capítulo seguinte de Vanguardas em retrocesso, "Gênero, classe, afetividade e pulsão criativa" Miceli ajusta sua lente para estudar duas figuras aparentemente opostas a Borges e Mario, sobretudo no que diz respeito às posições sociais ocupadas. Ricardo Güirdales e Tarsila do Amaral pertenciam a famílias endinheiradas e seguramente podiam se valer de tais trunfos para se colocarem na dianteira do campo artístico então incipiente. O que transforma tanto Tarsila quanto Güirdales em ocupantes de "posições em falso" (lembremos sempre que esta é a chave de entrada de Miceli nos autores pesquisados) em um cenário aparentemente bastante favorável são certas circunstâncias imprevistas, sobretudo familiares: uma saúde extremamente frágil e a posição secundária na linhagem, no caso do argentino, e um primeiro casamento malsucedido, com direito à educação solitária da filha, e a posição de única filha mulher após a morte da irmã, no caso da artista brasileira. Se no caso de Mario e Borges o celibato é encarado como uma escolha possibilitadora da versão intelectual por eles perseguida, agora Miceli atenta para o casamento enquanto estratégia capaz de garantir "condições excepcionalmente privilegiadas para tentarem virar o jogo a seu favor" (Miceli, 2012: 128-129). A escolha dos cônjuges, Adelina del Carril 
e Oswald de Andrade, figuras abastadas e de fácil circulação nos grandes salões, possibilitariam à pintora e ao escritor a estabilidade necessária para que perseguissem seus projetos individuais, convertendo-se em "agentes estratégicos no processo de substituição de importações culturais" (Miceli, 20I2: I26), dado o contato privilegiado com a produção vanguardista europeia em um momento em que a "nacionalização" da cultura era palavra de ordem em ambos os países.

Em "Artistas 'nacional-estrangeiros' na vanguarda sul-americana - Lasar Segall e Xul Solar", observamos o outro lado da moeda no que diz respeito às relações entre América e Europa. Os artistas de formação estrangeira são obrigados a ressignificar suas linguagens, a se adaptar aos interesses e aos padrões periféricos, ao gosto do mecenato influente e à voga artística local. O que chama a atenção nos dois casos analisados é a necessidade de infundir, em seus quadros, emblemas locais, como a criollidad e a negritude, de modo a tornar palatável a assimilação de suas técnicas europeias (apesar de Xul Solar ser argentino de nascimento, Miceli atribui a sua formação enquanto pintor às estadas na Europa). No capítulo, novamente vemos a fatura estética, que muitas vezes se pretende livre dos condicionantes circunstanciais, atada inapelavelmente à necessidade de marcar distinções e afirmar posições em um jogo social sem tréguas.

O último capítulo de Vanguardas, "Os inventores da sociologia 'científica' sul-americana - Florestan Fernandes e Gino Germani", chama a atenção logo de cara por ser o único texto que foge do marco dos movimentos culturais do início do século passado, sobretudo dos anos I920. Miceli não chega a explicar a inclusão do artigo, a princípio destoante, mas basta iniciarmos a leitura para logo percebermos que há interesses análogos a todos os outros. Em ambientes universitários cuja criação se deu sob os auspícios de frações das mesmas oligarquias que arrendaram as vanguardas estéticas, tornava-se quase impossível separar os desígnios universitários das necessidades de reprodução das classes dirigentes. Nesse panorama, as ciências sociais, e a sociologia em especial, encontraram uma série de barreiras que lhes impediam galgar os lugares mais altos do "establishment intelectual", principalmente a concorrência do ensaísmo e da crítica da cultura. É nessa atmosfera ainda bastante elitista que Florestan e Germani iniciam seus empreendimentos acadêmicos, com um porém fundamental: ao contrário de boa parte dos seus colegas, ambos eram destituídos de capital econômico e social. $\mathrm{O}$ argumento de Miceli caminha, assim, para indicar de que maneira os dois sociólogos foram capazes de se aproveitar da baixa consideração da disciplina de modo a converterem suas "posições em falso" em posições de prestígio no interior de uma carreira que ainda estava por se consolidar. A trajetória de Florestan e Germani, portanto, confunde-se com o processo de institucionalização da sociologia em seus países. Praticantes 
de uma disciplina desprotegida e sem o cabedal cultural necessário para enveredarem por outras searas mais afins com seus pares, os dois sociólogos recorreram ao amparo das tradições científicas estrangeiras e se empenharam com afinco na formação especializada em detrimento de outros ramos considerados por eles diletantes e aristocráticos. A campanha entusiasmada em prol de uma sociologia científica, expressa em "estilo empedrado, quase um dialeto cifrado" (Miceli, 20I2: 165), seria o respiro encontrado em um contexto bem pouco favorável aos "primos pobres" da disciplina.

Ao contrário dos capítulos anteriores, em que Miceli ainda recorre aos textos (ou às telas) dos autores estudados de modo a aprofundar sua análise, o capítulo sobre Florestan e Germani carece deste corpo a corpo. Este fato quiçá impeça que o autor perceba, por exemplo, certas tensões na forma particular com que os sociólogos incorporam as citadas tradições científicas forasteiras, talvez não tão "forçosamente estribadas na tradição estrangeira de trabalho monográfico" (Miceli, 2012: I66) e com mais matizes do que a mera e "apaixonada adesão ao universo de valores dos mestres estrangeiros" (Miceli, 2012: 167). Se é correto, como sugerimos no início desta resenha, que um dos méritos de Vanguardas em retrocesso reside na clareza com que persegue determinadas questões de pesquisa sempre de maneira articulada a uma metodologia muito bem definida, por outro lado o seu "passo em falso" tal- vez esteja, se não na pouca atenção dada aos textos e às ideias propriamente ditas (este é certamente o caso do último capítulo, ainda que não dos dois primeiros), na pouca disposição para se deixar surpreender pela fatura textual. Poesias, telas e monografias sociológicas são encaradas como se pouco, ou nada, pudessem tensionar ou problematizar da trajetória, posição social ou dos interesses individuais e de classe dos autores estudados. A passagem dos interesses para as obras, afinal, não é transparente, como, aliás, já lembrava Georg Lukács em seu clássico ensaio sobre a polêmica entre Balzac e Stendhal. Se o progressista, iluminista e antirromântico Stendhal era o grande crítico da Restauração, foi Balzac, reacionário, monarquista e a ela fiel quem retratou, do ponto de vista da forma literária, com mais profundidade crítica a aristocracia arrivista e pautada em privilégios nobiliárquicos. Como resume Lukács: "São estas as atitudes políticas dos dois escritores. Mas o mundo que cada um deles revive com a sua pena fala uma linguagem bastante diferente" (Lukács, I965: I3I). Esta observação, no entanto, apenas pretende apontar para outros caminhos possíveis que a obra de Sérgio Miceli suscita e faz pensar, e que não comprometem sua proposta, explícita desde o princípio do livro, cujo andamento se mantém sempre coerente.

Recebida em 22/08/20I3 Aprovada em I5/og/2013 


\section{REFERÊNCIAS BIBLIOGRÁFICAS}

Lukács, Georg. (1965). A polêmica entre Balzac e Stendhal. In: Ensaios sobre Literatura. Rio de Janeiro: Civilização Brasileira, p. II5-I37.

Andre Bittencourt é bacharel em Ciências Sociais pela Universidade Federal do Rio de Janeiro (UFRJ) e mestre em Sociologia pelo Programa de Pós-Graduação em Sociologia e Antropologia (PPGSA) da mesma instituição, onde atualmente também cursa seu doutorado sobre a obra de Pedro Nava. É autor de O Brasil e suas diferenças: uma leitura genética de Populações meridionais do Brasil (2013). 